\title{
O OLHO DO DONO ENGORDA O GADO? A RELAÇÃO ENTRE A PRESENÇA DO DONO NO SETOR DE PRODUÇÃO E A PRODUTIVIDADE
}

\author{
VENANCIO FILHO, Edmilson Alves ${ }^{1}$ \\ CIRIBELI, João Pauloº \\ MASSARDI, Wellington de Oliveira ${ }^{3}$ \\ MENDES, Wanderson de Almeida ${ }^{4}$ \\ MENDES, Wesley de Almeida ${ }^{5}$
}

\begin{abstract}
Recebido em: $2020.11 .18 \quad$ Aprovado em: 2021.04.29 ISSUE DOI: $10.3738 / 1982.2278 .3869$
RESUMO: O objetivo deste estudo foi analisar se a presença do dono dentro do setor de produção influencia na produtividade da empresa, além de verificar os determinantes que podem afetar nesse resultado. Para isso, utilizou-se o método quantitativo de regressão linear múltipla, em que a variável dependente usada foi a Produtividade e as variáveis independentes foram presença do dono, absenteísmo, número de funcionários, produção do dia anterior e horas trabalhadas. O objeto de estudo desta pesquisa foi a empresa Confecções Maria Magalhães, onde foi analisado um período de seis meses. O resultado desta pesquisa evidenciou, para este caso em específico, que a presença do dono não possui uma relação significativa com o aumento ou redução da produtividade.
\end{abstract}

Palavras-chave: Produtividade. Eficácia. Liderança.

\section{DOES THE EYE OF THE MASTER FATTENS HIS CATTLE? ANALYZING THE RELATIONSHIP BETWEEN THE PRESENCE OF THE OWNER IN THE PRODUCTION SECTOR AND THE PRODUCTIVITY OF THE FIRM}

\begin{abstract}
SUMMARY: The objective of this study was to analyze whether the presence of the owner within the production sector influences the company's productivity, in addition to verifying the determinants that may affect this result. For this, the quantitative method of multiple linear regression was used, in which the dependent variable used was Productivity and the independent variables were the presence of the owner, absenteeism, number of employees, production of the previous day and hours worked. The object of study of this research was the company Confecções Maria Magalhães, where a period of six months was analyzed. The result of this research showed, for this specific case, that the presence of the owner does not have a significant relationship with the increase or decrease in productivity.
\end{abstract}

Keywords: Productivity. Efficacy. Leadership.

\section{INTRODUÇÃO}

A gestão de pessoas pode ser considerada como vital para o sucesso das empresas (CHIAVENATO, 2009). Nisso, a liderança assume papel de destaque dentro das organizações, procurando estabelecer o comprometimento dos funcionários com os objetivos definidos pelas empresas, promovendo a competência, estimulando o trabalho em equipe ou criando afinidades

\footnotetext{
${ }^{1}$ Graduado em Administração.

${ }^{2}$ Doutor em Administração. Professor da UNIFAGOC e Gestor Municipal de Convênios - GMC da Prefeitura Municipal de Guiricema.

${ }^{3}$ Mestre em Administração pela Universidade Federal de Viçosa - UFV. Bacharel em Ciências Contábeis pela FAGOC.

${ }^{4}$ ORCID-ID http://orcid.org/0000-0002-5667-2346 Doutorando e Mestre em Administração com concentração na área Pública do Programa de Pós-Graduação em Administração da Universidade Federal de Viçosa (PPGADM/UFV). Membro do colegiado do curso de Administração da UNIFAGOC.

${ }^{5}$ Doutor em Administração com concentração na área Pública do PPGADM da Universidade Federal de Viçosa.
} 
entre os membros da organização e, consequentemente, motivando-os a alcançarem os objetivos estabelecidos, mediante o trabalho participativo e entusiasmado de todos.

O líder, por sua vez, deve ser escolhido mediante o nível de conhecimentos e habilidades relacionado com o trabalho a ser executado e a forma como este deve ser realizado. Para que a orientação do líder seja feita de forma clara e objetiva, ele deve realizar a tarefa na frente dos funcionários com o objetivo de expor o melhor método de execução (TAYLOR, 1999). Para Sobral e Furtado (2019), o contexto atual tem exigido um estilo de liderança mais colaborativo, buscando atender os novos arranjos organizacionais. Segundo Story (2020), com a pandemia da Covid-19, a necessidade de demonstrar credibilidade, coragem nas tomadas de decisões e empatia é ainda mais importante.

Diversos estudos sobre liderança foram realizados ao longo do tempo. Segundo Robbins (2005), alguns estudos enfatizam que os líderes são responsáveis por repassarem as atividades aos funcionários e ressaltam a importância do cumprimento dos prazos estabelecidos pela execução das tarefas, enfatizando que, ao dedicarem atenção aos funcionários, conseguem melhorar os resultados relacionados à produtividade.

Contudo, nem sempre é possível mensurar o quanto um funcionário está dedicando seus esforços ao trabalho, visto que essa análise é coberta de subjetividade. É possível dizer que ter uma equipe bem dirigida e gerenciada não garante que todos estejam em sintonia com as metas organizacionais, assim como nem sempre é possível o líder estar presente na empresa para acompanhar o processo e identificar os funcionários que não demonstram esforço durante a execução de suas funções.

Atribui-se à liderança uma relação direta com a produtividade, a qual, segundo Slack, Chambers e Johnston (2008), pode ser definida como a melhor utilização dos fatores envolvidos no processo de produção, relacionados aos inputs, transformação em outputs. Considera-se neste estudo, que a mão de obra é o principal fator de transformação de entradas em produtos finais, e consequentemente, o fator mais complexo de se gerenciar.

Assim, as empresas têm buscado, cada vez mais, capacitar os funcionários para serem auto gerenciados e não necessitarem de supervisão constante, levando em consideração aspectos relativos ao comprometimento dos funcionários, os quais dedicariam o máximo de esforço ao atingimento dos objetivos (ALMEIDA; PERETA, 2008; CARVALHAL, 2012; ROBBINS, 2005). Nesse sentido, até que ponto o ditado popular que diz: "O olho do dono é que engorda o gado" pode ser considerado verdadeiro?

O objetivo deste estudo consiste em verificar se existe ou não relação da presença do dono com a produtividade, além de analisar os determinantes capazes de influenciar nela. O presente 
trabalho tem como hipótese de que a presença do dono no processo produtivo aumenta a produtividade dos funcionários.

Assim, este estudo se justifica pela necessidade de compreender como a gestão de pessoas, através da presença do dono, pode influenciar na produtividade das empresas, reconhecendo a liderança como um fator determinante para a produtividade, pois, sem essa, dificilmente uma empresa conseguirá ser bem-sucedida ou sobreviver no mercado (MACEDO, 2012).

\section{REFERENCIAL TEÓRICO}

\subsection{Eficiência no processo produtivo: formas de medição e fatores que interferem na produtividade}

As definições de produtividade estão relacionadas com "fazer mais com menos recursos" (PARANHOS FILHO, 2012, p. 157), em que insumos devem ser combinados para fornecer uma saída; assim, produtividade refere-se ao melhor aproveitamento dos recursos no processo de produção (MOREIRA, 2008; GAITHER; FRAZIER, 2002), podendo ser obtida pela divisão da produção física em um determinado período de tempo, mediante a utilização dos inputs (fatores de produção), vinculados ao processo produtivo (FISCHER et al., 2011).

Nesse sentido, a produtividade passa a ser considerada "mais como uma medida de eficiência do processo de produção do que do processo produtivo de uma empresa" (MACEDO, 2012, p. 111). A partir dessa premissa, as empresas têm enfatizado a necessidade de melhorar constantemente a produtividade (em paralelo à qualidade), associada à redução de custos de produção (OLIVEIRA; PHILIPPI, 2013).

Uma das formas de se analisar a produtividade é pelo acompanhamento dos índices de eficiência produtiva das empresas, que podem ser obtidos a partir de medidas baseadas em insumos. "Quase todos os tipos de operações poderiam usar uma mistura de medidas de entradas e saídas, mas, na prática, a maioria usa uma ou outra" (SLACK; CHAMBERS; JOHNSTON, 2008, p. 350).

Para isso, existem diversas formas de medição e análise. A mais comum e utilizada é a proporção decorrente das saídas (ou outputs) sobre as entradas (inputs), que pode ser representada conforme explica Moreira (2008, p. 458) pela seguinte fórmula:

$$
\text { Produtividade }=\frac{\text { Quantidade de produtos ou serviços produzidos }}{\text { Quantidade de recursos utilizados }}(1)
$$

O mesmo autor expõe ainda que existem diversas medidas que podem ser usadas para se determinar a produtividade, sempre considerando um período de tempo específico para cada 
recurso utilizado no processo. Algumas formas de medição da produtividade dos recursos podem ser visualizadas no Quadro 1.

Assim, pode-se dizer que, para se calcular a eficiência produtiva, deve-se considerar o resultado final do processo e analisar sua relação com os recursos utilizados para a obtenção dos resultados.

Vale considerar que os processos produtivos têm por finalidade transformar entradas (inputs, que são os insumos do processo de produção, os quais podem ser considerados como materiais, informações, consumidores, instalações, pessoal, etc.) em saídas (outputs, que são os produtos e serviços), os quais são obtidos através do processo de transformação (SLACK; CHAMBERS; JOHNSTON, 2008).

Quadro 1 - Formas de medir a produtividade dos recursos utilizados no processo produtivo

\begin{tabular}{|c|c|}
\hline Recursos & Formas de medição \\
\hline Capital & Número de produtos produzidos dividido pelo valor do ativo. \\
\hline Materiais & Número de produtos produzidos dividido pelo desembolso feitos com materiais. \\
\hline Mão de obra direta & Número de produtos produzidos dividido pelas horas de mão de obra direta. \\
\hline Gastos gerais & $\begin{array}{c}\text { Número de produtos produzidos dividido pelo dinheiro dispendido com gastos } \\
\text { gerais. }\end{array}$ \\
\hline
\end{tabular}

Fonte: Elaborado pelos autores com base em Moreira (2008, p. 459).

A Figura 1 ilustra o processo de produção que considera as entradas, o processo de transformação e as saídas do processo, além de apresentar o controle como parte importante do processo.

Figura 1 - Processo de produção

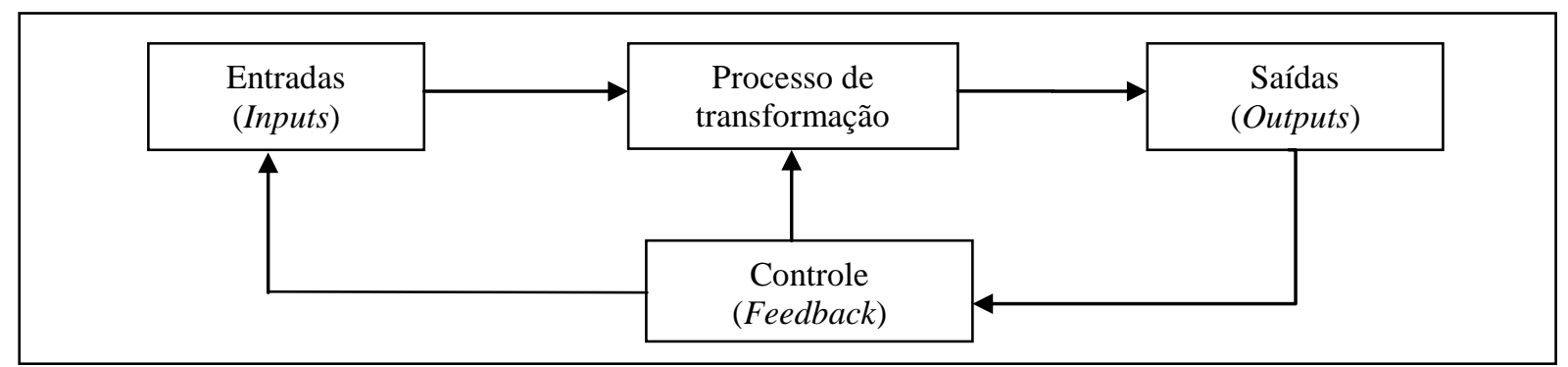

Fonte: Elaborada pelos autores, com base em Slack, Chambers e Johnston (2008); Moreira (2008); Gaither e Frazier (2002).

Dentro do processo de transformação, onde insumos são convertidos em saídas, diversos fatores podem afetar a produtividade das empresas, portanto, devem ser considerados e gerenciados de forma a assegurar que o processo sofra o mínimo de interferências possível, garantindo, assim, que a produtividade possa fluir e ocasionar ganhos em eficiência para a empresa. 
Para que essas interferências sejam minimizadas, a função de controle, ou feedback, assume papel de grande importância ao longo do processo produtivo. Esse controle tem por objetivo identificar quais fatores podem interferir na produtividade das empresas, buscando meios de minimizar os impactos decorrentes, que possam afetar a eficiência do processo. Esses fatores que exercem influência na produtividade das empresas podem ser classificados como internos ou externos: os internos são as outras áreas funcionais das empresas como marketing, finanças, recursos humanos; e os externos são fatores como políticos e regulações governamentais, tecnologia, competição e as condições gerais da economia (MOREIRA, 2008).

Quando se fala em aumento da produtividade nota-se ainda que vários outros fatores passam a interferir no nível de produção das empresas, tais como volume e variedade dos produtos, índice de absenteísmo, disponibilidade de máquinas para uso, motivação e liderança, dentre outros (SLACK; CHAMBERS; JONHSTON, 2008; CHIAVENATO, 2008). Pode-se perceber através do Quadro 2, como esses fatores podem restringir a capacidade produtiva das empresas.

Quadro 2 - Fatores que podem restringir a capacidade produtiva das empresas

\begin{tabular}{|c|l|}
\hline Fatores & \multicolumn{1}{c|}{ Impactos } \\
\hline $\begin{array}{c}\text { Volume de } \\
\text { produtos }\end{array}$ & $\begin{array}{l}\text { Baixo volume implica um fluxo de produção descontinuado, baixa padronização, } \\
\text { enfase no projeto do produto. } \\
\text { Alto volume implica fluxo de produção contínuo, alta padronização, e ênfase no } \\
\text { projeto do processo. }\end{array}$ \\
\hline $\begin{array}{c}\text { Variedade de } \\
\text { produtos }\end{array}$ & $\begin{array}{l}\text { êixo volume implica um fluxo de produção descontinuado, baixa padronização, } \\
\text { Alto volume implica fluxo de produção contínuo, alta padronização, e ênfase no } \\
\text { projeto do processo. }\end{array}$ \\
\hline $\begin{array}{c}\text { Absenteísmo } \\
\text { Indispone de faltas ou ausências, ou seja, a totalidade de funcionários disponíveis para } \\
\text { máquinas }\end{array}$ & $\begin{array}{l}\text { Quantidade de máquinas e equipamentos que se encontram disponíveis para uso, ou } \\
\text { seja, não estão paradas por necessidade de reparos ou preparação para uma nova tarefa. }\end{array}$ \\
\hline $\begin{array}{c}\text { Motivação e } \\
\text { liderança }\end{array}$ & $\begin{array}{l}\text { Influência do líder como capaz de inspirar o comportamento das pessoas, com o intuito } \\
\text { de motivar os funcionários a buscarem melhores resultados. }\end{array}$ \\
\hline
\end{tabular}

Fonte: Elaborado pelos autores com base em Slack, Chambers e Johnston, (2008); Maximiano (2012); Chiavenato (2008).

Para a produtividade da mão de obra, Gaither e Frazier (2002) expõem que três fatores são os mais importantes: o desempenho do funcionário; a tecnologia (máquinas, ferramentas e os métodos de produção); e a qualidade dos produtos. De todas as variáveis capazes de interferir na produtividade da mão de obra, a motivação pode ser considerada a mais complexa. Isso se deve ao fato de que apenas as necessidades não satisfeitas podem ser consideradas como um fator motivador pelo funcionário.

Paralelo a isso, tem-se que o aumento de produtividade, associado a uma melhor utilização de fatores tecnológicos, é tão significativo quanto os aspectos relacionados ao desempenho do funcionário no trabalho, e que, quando se evita o desperdício, retrabalhos e 
redução de defeitos, afeta-se positivamente a produção, trazendo aumentos cada vez mais significativos de produtividade (MARQUES, 1995; GAITHER; FRAZIER, 2002).

\subsection{Motivação e Liderança}

A liderança pode ser entendida como um processo cujo objetivo é influenciar outras pessoas (CARAVANTES; PANNO; KLOEKNER, 2005; DRUCKER, 1967). De acordo com Silva (2008, p. 229), "liderança é o processo de dirigir e influenciar as atividades de grupos no sentido de alcançar os objetivos em uma dada situação". Nesse sentido, os líderes são capazes de direcionar as ações dos funcionários conforme seu planejamento.

Por sua vez, o processo de liderar pode acontecer de diversas formas e ambientes, seja por meio do encorajamento ou comprometimento dos funcionários com os objetivos da empresa, ou até mesmo pelo exemplo de dedicação e poder de convencimento que o líder demostra (CARAVANTES; PANNO; KLOEKNER, 2005).

Vale salientar que o papel do líder não se resume aos aspetos relacionados à resolução de conflitos e controle: ele se torna mais amplo ao enfatizar a motivação dos funcionários (CARAVANTES; PANNO; KLOEKNER, 2005). Ressalta-se ainda que os supervisores possuem um papel importante no processo de transferência do aprendizado desenvolvido pelos funcionários em treinamentos para a prática do trabalho (GOVAERTS et al., 2017).

Buscando melhorar os resultados organizacionais, os líderes possuem 5 (cinco) tipos de poderes que os auxiliam a desenvolver a liderança nas organizações. Esses tipos de poderes e os objetivos decorrentes da sua utilização podem ser visualizados no Quadro 3.

Quadro 3 - Poderes dos Líderes nas empresas

\begin{tabular}{|l|l|}
\hline \multicolumn{1}{|c|}{ Tipos de poderes } & \multicolumn{1}{c|}{ Objetivos } \\
\hline Poder de Recompensa & $\begin{array}{l}\text { Oferecer algo de valor, um resultado positivo, como meio de influenciar o } \\
\text { comportamento de outras pessoas. }\end{array}$ \\
\hline Poder Coercitivo & $\begin{array}{l}\text { Direito de punir ou de reter resultados positivos, como meio de influenciar o } \\
\text { comportamento de outras pessoas. }\end{array}$ \\
\hline Poder de Especialização & $\begin{array}{l}\text { Influenciar o comportamento de outras pessoas por causa do conhecimento } \\
\text { específico ou do entendimento que alguém detém. }\end{array}$ \\
\hline Poder de Referência & $\begin{array}{l}\text { Influenciar o comportamento de outras pessoas por causa de seu desejo de se } \\
\text { identificar pessoal e positivamente com alguém admirado. }\end{array}$ \\
\hline Poder Legítimo & $\begin{array}{l}\text { Influenciar o comportamento de outras pessoas em virtude dos direitos do } \\
\text { cargo ou função ocupada. }\end{array}$ \\
\hline
\end{tabular}

Fonte: Elaborado pelos autores com base em Silva (2008, p. 229-230).

Nesse sentido, ressalta-se que as práticas e direcionamentos atribuídos aos líderes no que se refere à motivação e à liderança podem interferir na produtividade, uma vez que a satisfação e a produtividade podem ser consideradas como um fator que influencia o desempenho das empresas (BECKER et al., 2001 citados por FERNANDES et al., 2013). Story (2020) explica 
sobre a importância do papel do líder em tempos de pandemia para a redução do estresse e insegurança no trabalho, o que pode afetar o desempenho do trabalhador.

Os estudos de Hawthorne podem ser considerados como fundamentais ao se analisarem as contribuições decorrentes dele, para entender a importância da liderança na motivação dos funcionários. A Teoria das Relações Humanas (MOTTA; VASCONCELOS, 2006; ETZIONI, 1973; COLTRO, 2015) enfatizou que a produtividade não era apenas consequência da padronização dos processos produtivos, do estudo de tempos e movimentos como sugeriam Taylor e Ford, e que melhores resultados na eficiência produtiva são decorrentes também do relacionamento dos funcionários com os supervisores, constatando-se resultados significativos e, talvez, melhores - quando comparados aos aspectos técnicos dos processos produtivos, ou seja, a melhoria da eficiência produtiva estava associada à atenção dispensada, pelos supervisores e pesquisadores envolvidos no experimento (SILVA, 2008; COLTRO, 2015). As principais conclusões e contribuições do experimento de Hawthorne podem ser visualizadas no Quadro 4.

Quadro 4 - Principais conclusões e contribuições do Experimento de Hawthorne

\begin{tabular}{|c|l|}
\hline Motivação & $\begin{array}{l}\text { Os empregados não eram motivados somente por fatores externos, como pagamento e } \\
\text { condições físicas do ambiente de trabalho; havia fatores psicológicos que afetavam a } \\
\text { produtividade, e não só fisiológicos. }\end{array}$ \\
\hline $\begin{array}{c}\text { Intervalos } \\
\text { durante o } \\
\text { processo }\end{array}$ & $\begin{array}{l}\text { Pausas no trabalho demonstram bons resultados no que se refere à produtividade dos } \\
\text { operários, mas não poderiam ser analisadas como elemento isolado. }\end{array}$ \\
\hline Sociabilidade & $\begin{array}{l}\text { O relacionamento social entre as operárias e a supervisão provocava condições de trabalho } \\
\text { que favoreciam o aumento da produtividade das funcionárias. }\end{array}$ \\
\hline $\begin{array}{c}\text { Liderança } \\
\text { participativa }\end{array}$ & $\begin{array}{l}\text { Havia tendência de liderança em grupos mais sociáveis, o que significava maior cooperação } \\
\text { do grupo para ultrapassar dificuldades do trabalho; }\end{array}$ \\
\hline $\begin{array}{c}\text { Produtividade } \\
\text { A satisfação (ou insatisfação) com as tarefas realizadas afetava fortemente o resultado da } \\
\text { produção e a intenção dos operários. }\end{array}$ \\
\hline $\begin{array}{c}\text { Liderança } \\
\text { informal }\end{array}$ & $\begin{array}{l}\text { Os grupos informais (organização informal) afetavam mais os resultados de produção do que } \\
\text { as determinações da alta administração. }\end{array}$ \\
\hline $\begin{array}{c}\text { Grupos } \\
\text { informais }\end{array}$ & $\begin{array}{l}\text { O grupo exercia enorme poder sobre o indivíduo, isto é, o comportamento do indivíduo era } \\
\text { fortemente afetado pelas diretrizes estabelecidas pelo grupo. }\end{array}$ \\
\hline $\begin{array}{c}\text { Influência do } \\
\text { grupo }\end{array}$ & $\begin{array}{l}\text { O volume de produção gerado por um operário não dependia de sua habilidade ou } \\
\text { inteligência, mas da restrição do grupo ao qual pertencia. }\end{array}$ \\
\hline $\begin{array}{c}\text { Restrição a } \\
\text { inovações }\end{array}$ & $\begin{array}{l}\text { Inovações e melhorias técnicas introduzidas pela administração da organização não eram bem } \\
\text { vistas pelos operários, que se sentiam explorados nessas condições: produzir mais ganhando o } \\
\text { mesmo salário. }\end{array}$ \\
\hline
\end{tabular}

Fonte: Elaborado pelos autores com base em Silva (2008, p. 193).

Assim, pode-se dizer que o funcionário, quando percebe que os supervisores notam e até mesmo reconhecem o esforço dedicado por ele para a obtenção de melhores resultados em termos de produtividade, acaba por melhorar ainda mais seu desempenho produtivo. "Portanto, o líder tem um papel fundamental sobre isso; a motivação e crescimento do capital humano das empresas, pois é ele o responsável para esse apoio" (SILVA; MESQUISTA; FERREIRA, 2015, p. 92). Logo, considera-se a importância do papel de liderança que os supervisores devem exercer para se alcançar os resultados satisfatórios. 
Drucker (1967) ainda aponta sobre a importância da tomada de decisão dos líderes como meio de se atingir resultados eficazes. Um líder que sabe como manter sua equipe motivada e que toma as decisões com rapidez e eficácia, aumenta a possibilidade de a organização atingir melhores resultados.

\section{MÉTODO}

Como unidade empírica de análise foi escolhido o processo produtivo da Confecções Maria Magalhães, localizada no município de Dona Euzébia, em Minas Gerais. Foram analisados 6 (seis) meses de produção: setembro, outubro e novembro de 2015, março, abril e maio de 2016. A opção por esses meses para análise considerou os períodos que não sofrem interferência de interrupção para férias, as quais, pela cultura da empresa, ocorrem de forma coletiva, distribuídas pelos meses de dezembro, janeiro e fevereiro.

A fim de alcançar o objetivo proposto, foi realizada uma análise de regressão linear múltipla. Este método é utilizado para verificar a relação entre uma única variável dependente e duas ou mais variáveis independentes ou preditoras. Foi utilizada variável Dummy, a qual procura atribuir a variáveis quantitativas uma variável qualitativa, para mensurar a presença do dono na produtividade. O objetivo da análise de regressão linear múltipla é mensurar os efeitos das variáveis independentes, sobre a variável dependente (HAIR et al., 2009). Sendo assim, o modelo de regressão linear múltipla é representado pela equação:

$$
Y_{i}=\beta_{0}+\beta_{1} X_{1}+\beta_{2} X_{2}+\beta_{n} X_{n}+e(2)
$$

Onde $Y_{i}$ representa a variável dependente; $\beta_{0}$, o intercepto da regressão; $\beta_{1}$ mostra o coeficiente angular da variável $1 ; X_{1}$ representa a variável independente $1 ; \beta_{2}$, o coeficiente angular da variável $2 ; X_{2}$, a variável independente 2 ; e $e$, o erro estocástico.

Para estimar os valores dos $\beta$ 's foi utilizado o MQO (mínimos quadrados ordinários), o qual objetiva minimizar a soma dos quadrados, procurando resumir a relação linear entre a variável dependente sobre as variáveis independentes, uma vez que procura minimizar os erros de estimação entre os valores observados e os preditos (GUJARATI; PORTER, 2011; STOCK; WATSON, 2004), ou seja, para uma dada amostra, o MQO apresenta estimativas singulares de $\widehat{\beta_{1}} \mathrm{e} \widehat{\beta_{2}}$ " (GUJARATI, 2006, p. 49-50) por meio das seguintes equações:

$$
\begin{aligned}
& \widehat{\beta_{1}}=\frac{\sum X_{i}^{2} \sum Y_{i}-\sum X_{i} \sum X_{i} Y_{i}}{n \sum X_{i}^{2}-\left(\sum X_{i}\right)^{2}} \\
& \widehat{\beta_{2}}=\frac{\sum X_{i} Y_{i}}{\sum X_{i}^{2}}
\end{aligned}
$$


A significância dos $\beta$ 's foi testada mediante o teste T, cuja finalidade é "verificar a veracidade ou a falsidade de uma hipótese nula" (GUJARATI, 2006, p. 135), com o objetivo de aceitar ou rejeitar a $\mathrm{H}_{0}$, por meio da seguinte equação:

$$
t=\frac{\widehat{\beta_{2}}-\beta_{2}}{e p\left(\widehat{\beta_{2}}\right)}
$$

As variáveis utilizadas na regressão linear múltipla estão apresentadas no Quadro 5, assim como o resultado teórico esperado, de forma a determinar a relação entre as variáveis independentes e a variável dependente.

Quadro 5 - Variáveis utilizadas no cálculo da regressão múltipla

\begin{tabular}{|c|c|c|c|}
\hline Variável & Descrição & Sinal esperado & Fonte \\
\hline Produtividade & Variável dependente & Não se aplica & $\begin{array}{c}\text { Documentos internos da } \\
\text { empresa }\end{array}$ \\
\hline $\begin{array}{l}\text { Produção dia } \\
\text { anterior }\end{array}$ & Variável independente & $\begin{array}{c}\text { Positiva, pois espera-se que haja } \\
\text { economia de escala }\end{array}$ & $\begin{array}{l}\text { Documentos internos da } \\
\text { empresa }\end{array}$ \\
\hline $\begin{array}{l}\text { Número de } \\
\text { funcionários }\end{array}$ & Variável independente & $\begin{array}{l}\text { Positiva, pois espera-se que } \\
\text { mediante da contratação de um } \\
\text { funcionário a produtividade } \\
\text { aumente }\end{array}$ & $\begin{array}{l}\text { Documentos internos da } \\
\text { empresa }\end{array}$ \\
\hline $\begin{array}{l}\text { Horas } \\
\text { trabalhadas }\end{array}$ & Variável independente & \begin{tabular}{|c|} 
Positiva, espera-se que quanto \\
mais horas trabalhadas, maior será \\
a produtividade
\end{tabular} & $\begin{array}{l}\text { Documentos internos da } \\
\text { empresa }\end{array}$ \\
\hline Absenteísmo & Variável independente & $\begin{array}{l}\text { Negativa, a ausência de um } \\
\text { funcionário pode influenciar na } \\
\text { produtividade }\end{array}$ & $\begin{array}{l}\text { Documentos internos da } \\
\text { empresa }\end{array}$ \\
\hline $\begin{array}{l}\text { Presença do } \\
\text { dono }\end{array}$ & $\begin{array}{c}\text { Variável Dummy, assumindo o } \\
\text { valor 1(um) quando a proprietária } \\
\text { está na empresa e } 0 \text { (zero) quando } \\
\text { está ausente }\end{array}$ & $\begin{array}{c}\text { Positiva, a presença do dono } \\
\text { influencia e melhora a eficiência } \\
\text { da produtividade }\end{array}$ & $\begin{array}{l}\text { Dados da pesquisa, obtidos } \\
\text { por meio da observação } \\
\text { direta dos autores }\end{array}$ \\
\hline
\end{tabular}

Fonte: Elaborado pelos autores.

Nesse sentido, o uso da regressão teve como objetivo explicar o comportamento das variáveis independentes (presença do dono, absenteísmo, número de funcionários e horas trabalhadas) em relação à variável dependente (produtividade).

A escolha dessas variáveis encontra justificativa na literatura, através de autores como Slack, Chambers, Johnston (2008), Moreira, (2008), Gaither, Frazier (2002), Chiavenato (2008), pois são mencionadas como fatores que exercem influência na produtividade das empresas, podendo até mesmo representar motivos que a restringem, como o absenteísmo, por exemplo. Já o número de horas trabalhadas e o número de funcionários sugerem que, quanto mais horas se trabalham, maior será o montante de peças produzidas.

Com relação à quantidade de peças produzidas, atribuiu-se um peso que considerou o tempo de fabricação de cada produto na linha de produção, utilizando o método de rateio, cujo objetivo é reduzir a arbitrariedade, ou o subjetivismo (MARTINS, 2010). Para a atribuição dos 
pesos foi levada em consideração o grau de dificuldade de diversos produtos na linha de produção, se baseando no tempo médio de fabricação, como se pode observar na Tabela 1.

Tabela 1 - Peso atribuído aos produtos na linha de produção

\begin{tabular}{ccc}
\hline Produto & Tempo Médio em minutos & Pesos \\
\hline Vestido & 3.606 & 0,4 \\
\hline Chemise & 2.671 & 0,3 \\
\hline Camisa & 1.613 & 0,2 \\
\hline Regata & 1.110 & 0,1 \\
\hline Total & 8.999 & 1,0
\end{tabular}

Fonte: Dados da pesquisa.

A variável independente Presença do dono possui dados não métricos, sendo necessária a transformação dos dados nominais com codificação dicotômica denominada variável Dummy. Esta é usada para explicar o efeito que diferentes níveis de uma variável não métrica têm na previsão da variável dependente (HAIR et al., 2009).

Foram realizados os testes de Breush-Pagan e de White para verificar a homocedasticidade, os testes de Shapiro-Wilk e de Shapiro-Francia para verificar a normalidade dos resíduos, o teste Variance Inflation Factor (VIF) para identificar presença de multicolineariedade, e o teste $\mathrm{F}$ para testar a significância global do modelo de regressão lineal múltipla.

\section{RESULTADO E DISCUSSÃO}

Inicialmente, buscou-se analisar os dados demográficos dos funcionários do setor de produção, que, em sua maioria, é composto por mulheres $(85 \%)$ sendo que isto é uma característica do setor de confecções, ressalta-se que na atualidade a empresa possui 30 funcionários neste setor. Com relação à idade, observou-se que 55\% possuem idade de 36 a 60 anos e 45\%, de 18 a 34 anos, retratando experiência profissional, além de outras informações que podem ser visualizadas na Tabela 2.

Tabela 2 - Aspectos demográficos da empresa

\begin{tabular}{ccc}
\hline Gênero & Funcionários \% & Acumulativo \\
Masculino & $15 \%$ & $15 \%$ \\
\hline Feminino & $85 \%$ & $100 \%$ \\
\hline Total & $100 \%$ & \\
\hline Idade & Funcionários \% & Acumulativo \\
\hline Até 24 anos & $20 \%$ & $20 \%$ \\
\hline De 25 a 35 & $25 \%$ & $45 \%$ \\
\hline De 36 a 45 & $25 \%$ & $70 \%$ \\
\hline De 45 a 60 & $30 \%$ & $100 \%$ \\
\hline Total & $100 \%$ & \\
\hline
\end{tabular}

Fonte: Dados da pesquisa.

Nucleus, v.18, n.1, abr. 2021. 
Foram realizados testes de homocedasticidade, normalidade dos resíduos, multicolineariedade, e de significância global do modelo. De acordo com os testes de BreuschPagan e de White, pode-se aceitar a hipótese nula de homocedasticidade. Os testes de homocedasticidade podem ser visualizados no Quadro 6.

Quadro 6 - Testes de homocedasticidade do modelo de regressão

\begin{tabular}{|c|c|}
\hline Breusch-Pagan & White \\
\hline chi2 $(1)=3,06$ & 13,35856 Chi-sq (19) \\
\hline Prob $>$ chi $2=0,0804$ & P-value $=0,8197$ \\
\hline
\end{tabular}

Fonte: Resultados da pesquisa.

Foram realizados também testes para analisar a normalidade dos resíduos do modelo de regressão. Tanto o teste de Shapiro-Wilk, quanto o teste de Shapiro-Francia aceitaram a hipótese nula de que os resíduos do modelo possuem distribuição normal. Os testes de normalidade podem ser visualizados na Tabela 3.

Tabela 3 - Testes de normalidade dos resíduos

\begin{tabular}{lccccc}
\hline \multicolumn{7}{c}{ Teste de normalidade de Shapiro-Wilk } \\
\hline Variável & Obs. & $\mathbf{W}$ & $\mathbf{V}$ & $\mathbf{z}$ & Prob>z \\
resíduos & 128 & 0,993 & 0,682 & $-0,859$ & 0,805 \\
\hline \multicolumn{7}{c}{ Teste de } & normalidade de Shapiro-Francia \\
\hline Variável & Obs. & $\mathbf{W}$ & $\mathbf{V}$ & $\mathbf{z}$ & Prob>z \\
resíduos & 128 & 0,991 & 0,952 & $-0,099$ & 0,540 \\
\hline
\end{tabular}

Fonte: Resultados da pesquisa.

Para analisar a existência de multicolineariedade, foi utilizado o teste de Variance Inflation Factor (VIF), que indicou a ausência de multicolineariedade no modelo de regressão linear múltipla, conforme demonstrado na Tabela 4.

Tabela 4 - Teste de multicolineariedade.

\begin{tabular}{lcc}
\hline Variáveis & VIF & 1/VIF \\
\hline Número de funcionários & 1,47 & 0,682155 \\
Horas Trabalhadas & 1,42 & 0,703673 \\
Absenteísmo & 1,04 & 0,957897 \\
Produção dia anterior & 1,03 & 0,967796 \\
Presença do dono & 1,02 & 0,977186 \\
\hline VIF médio & 1,20 & \\
\hline
\end{tabular}

Fonte: Resultados da pesquisa.

Após a realização dos testes dos pressupostos de regressão, foi possível avançar com a análise. Na Tabela 5, pode-se visualizar os coeficientes do modelo de regressão. O teste $\mathrm{F}$ indica 
que o modelo geral apresenta significância global a nível de $1 \%$, e o R quadrado indica que 23,39\% da variação da variável dependente pode ser explicada pelas variáveis independentes. A fim de garantir maior robustez, o modelo de regressão foi estimado utilizando erros padrão robustos.

Tabela 5 - Coeficientes do modelo de regressão

\begin{tabular}{lrrr}
\hline Variáveis & Coeficiente & $\begin{array}{r}\text { Erros Padrão } \\
\text { Robustos }\end{array}$ & P>|t| \\
\hline Produção dia anterior & $0,298^{* * *}$ & 0,077 & 0,000 \\
Número de funcionários & $-2,282$ & 1,640 & 0,166 \\
Horas Trabalhadas & $0,392 * * *$ & 0,067 & 0,000 \\
Absenteísmo & $-0,039$ & 0,213 & 0,855 \\
Presença do dono & 4,398 & 3,240 & 0,177 \\
Intercepto & 13,763 & 28,693 & 0,632 \\
\hline
\end{tabular}

Fonte: Resultados da pesquisa.

Nota: $* * *$ Significativo a nível de $1 \%$.

Diante os resultados do modelo de regressão linear múltipla, pôde-se constatar que a presença do dono não foi significativa para o aumento ou redução da produtividade da empresa. Este resultado responde o objetivo principal deste estudo, apontando que a presença do dono não afeta a produtividade da empresa, contrariando a expectativa teórica de que a presença do dono faria diferença na produtividade empresarial, como apontado nos estudos de Taylor (1999), Sobral e Furtado (2019) e Story (2020).

Todavia, a produção do dia anterior apresentou coeficiente positivo em relação à produtividade a nível de significância de $1 \%$, ou seja, o aumento da produção do dia anterior contribui para que a produtividade também aumente. Este resultado pode estar relacionado ao fato de a produção do dia anterior apresentar características semelhantes ao do dia seguinte, como relação de outputs e inputs.

A variável horas trabalhadas também foi significativa a nível de $1 \%$, apresentando um efeito positivo sobre a produtividade. Esse resultado indica que o número de horas trabalhadas dentro da empresa onde foi realizado o estudo implica no aumento ou redução da produtividade.

As demais variáveis (número de funcionários e absenteísmo), assim como a variável presença do dono, não apresentaram significância no modelo de regressão linear múltipla, indicando que tais variáveis não apresentam efeito sobre a variável dependente.

Para responder o objetivo proposto para este artigo, foi levantada a hipótese de que a presença do dono no processo produtivo é um fator capaz de influenciar a produtividade da empresa. Assim, pode-se dizer que as variáveis "produtividade" e "presença do dono" não 
apresentaram relação entre si, não existindo influência direta da variável independente "presença do dono" sobre a dependente. Entretanto, admite-se a existência de outras variáveis determinante que explicam a variável dependente escolhida para análise. Dessa forma, rejeita-se a hipótese analisada.

\section{CONSIDERAÇÕES FINAIS}

O objetivo do trabalho foi analisar a relação da presença do dono com a produtividade, buscando identificar os fatores que influenciam nos resultados produtivos da empresa estudada.

Diante o exposto, foi possível observar que a variável presença do dono não afeta diretamente a variável dependente (produtividade), caracterizando, assim, a inexistência de uma influência significativa relacionada ao aumento ou à redução da produção. Ressalta-se que o fato de não ser verificada a ocorrência significativa para este caso não significa que o mesmo resultado será encontrado em outras empresas, uma vez que as organizações possuem realidades diferentes e, consequentemente, as formas de quantificação das variáveis serão diferente para cada realidade no Brasil, seja pelo porte, segmento do setor produtivo ou, até mesmo, pelo perfil do próprio empresário. Constatou-se ainda que, outras variáveis utilizadas analisadas afetam a produtividade, indicando outros elementos determinantes para a produtividade da empresa.

É importante salientar sobre a importância da necessidade de treinamento e adaptação às regras e à cultura organizacional da empresa, demandando um período de adaptação; e, somente após esse período, ocorreria um aumento significativo de produtividade.

Este estudo teve como limitação o fato de não levar em consideração fatores de ordem qualitativa e fatores mais subjetivos como a liderança, a motivação dos funcionários, aspectos de qualidade dos produtos, por serem variáveis mais complexas de se trabalhar, dada a dificuldade de serem verificados, por envolverem uma maior subjetividade no seu tratamento. Para estudos futuros, sugere-se a inserção dessas variáveis no modelo criado.

\section{REFERÊNCIAS}

ALMEIDA, M. R.; PERETA, M. J. Formação de equipes auto-gerenciáveis: uma análise prática. In: ENCONTRO NACIONAL DE ENGENHARIA DE PRODUÇÃO, 28. ENEGEP. [Anais...]. Rio de Janeiro, 2008.

CARAVANTES, G. R.; PANNO, C. C.; KLOECKNER, M. C. Administração: teorias e processos. s. ed. São Paulo: Pearson Prentice Hall, 2005.

CARVALHAL, F. Estilo de Liderança de Jovens Empreendedores: um estudo de auto percepção dos empreendedores da cidade de Aracaju - Sergipe. 2012. 169f. Monografia (Graduação em Administração de Empresas). Centro de Ciências Sociais e Aplicadas; Departamento de Administração. Universidade Federal de Sergipe, São Cristóvão, 2012. 
CHIAVENATO, I. Planejamento e controle da produção. 2. ed. São Paulo: Manole, 2008.

CHIAVENATO, I. Administração de recursos humanos: fundamentos básicos. 7. ed. São Paulo: Manole, 2009.

COLTRO, A. Teoria geral da administração. Curitiba: InterSaberes, 2015.

DRUCKER, P. F. The Effective Executive. Londres: William Heinemann Ltd., 1967.

ETZIONI, A. Organizações complexas. São Paulo: Atlas, 1973.

FERNANDES, B. H. R. et al. Os impactos das percepções e atitudes dos funcionários sobre a produtividade e qualidade em empresas de manufatura. Base - Revista de Administração e Contabilidade da Unisinos, Rio Grande do Sul, v.10, n. 3, set. 2013.

FISCHER, A. et al. Produção e produtividade de leite do oeste catarinense. RACE, Unoesc, v. 10, n. 2, p. 337 - 362, jul./dez. 2011.

GAITHER. N.; FRAZIER, G. Administração da produção e operações. 8. ed. São Paulo: Pioneira Thompson Learning, 2002.

GOVAERTS, N. et al. A Supervisors' Perspective on Their Role in Transfer of Training. Human Resource Development Quarterly, v. 28, n. 4, p. 515-552, maio, 2017.

GUJARATI, D. N. Econometria básica. 5. ed. Rio de Janeiro: Elsevier, 2006.

GUJARATI, D. N.; PORTER, D. C. Econometria Básica. 5. ed. Porto Alegre: Bookman, 2011.

HAIR, J. F. et al. Análise multivariada de dados. 6. ed. Porto Alegre: Bookman, 2009.

MACEDO, M. M. Gestão da produtividade nas empresas. Revista Organização Sistêmica, Curitiba, v. 1, n. 1, jun. 2012.

MARQUES, I. Produtividade alavanca para a competitividade. 1. ed. São Paulo: Edicon, 1995.

MARTINS, E. Contabilidade de custos. 10. ed. São Paulo: Atlas, 2010.

MAXIMIANO, A. C. A. Teoria geral da administração. 2. ed. São Paulo: Atlas, 2012.

MOREIRA, D. A. Administração da produção e operações. 2. ed. São Paulo: Cengage Learning, 2008.

MOTTA, F. C. P; VASCONCELOS, I. S. G. Teoria geral da administração. 3. ed. São Paulo: Thomson Learning, 2006.

OLIVEIRA, A. O.; PHILIPPI, D. A. Estratégias orientadas para a redução do lead time: estudo de caso na fábrica porto dos sonhos. SIMPOI: 2013, São Paulo, SP. Anais... São Paulo, SP: FGV-EAESP, 2013.

PARANHOS FILHO, M. Gestão da produção industrial. 1. ed. Curitiba: InterSaberes, 2012. ROBBINS, S. P. Comportamento organizacional. 11. ed. São Paulo: Pearson Prentice Hall, 2005. 
SILVA, R. O. Teorias da administração. São Paulo: Pearson Prentice Hall, 2008.

SILVA, W. T.; MESQUITA, E. O.; FERREIRA, S. K. C. Impactos positivos da liderança no processo produtivo. E3 - Revista de Economia, Empresas e Empreendedores na CPLP, v. 1, n. 2. 2015.

SLACK, N.; CHAMBERS, S.; JOHNSTON, R. Administração da produção. 2. ed. São Paulo: Atlas, 2008.

SOBRAL, F.; FURTADO, L. A liderança pós-heroica: Tendências atuais e desafios para o ensino de liderança. Revista de Administração de Empresas, São Paulo, vol. 59, n. 3, maio/jun. 2019.

STOCK, J. K.; WATSON, M. W. Econometria. São Paulo: Addison Wesley, 2004.

STORY, J. Liderança em tempos de Covid-19. GV-executivo, São Paulo, v. 19, n. 3, maio/jun. 2020.

TAYLOR, F. W. Princípios de administração científica. São Paulo: Atlas, 1999. 